Research article

\title{
Assessment of an aerobic granular sludge system in the presence of pharmaceutically active compounds by quantitative image analysis and chemometric techniques
}

\author{
Cristiano S. Leal ${ }^{\text {a }}$, Mariana Lopes ${ }^{\text {a }}$, Angeles Val del Río ${ }^{\text {a,b }}$, Cristina Quintelas ${ }^{\text {a }}$, Paula M. \\ L. Castro ${ }^{c}$, Eugénio C. Ferreira ${ }^{a}$, A. Luís Amaral ${ }^{\mathrm{a}, \mathrm{d}, \mathrm{e}}$, Daniela P. Mesquita ${ }^{\mathrm{a}, *}$ \\ ${ }^{a}$ CEB - Centre of Biological Engineering, Universidade do Minho, Campus de Gualtar, 4710-057, Braga, Portugal \\ ${ }^{\mathrm{b}}$ CRETUS Institute, Department of Chemical Engineering, Universidade de Santiago de Compostela, E-15705, Santiago de Compostela, Spain \\ ${ }^{\mathrm{c}}$ Universidade Católica Portuguesa, CBQF - Centro de Biotecnologia e Química Fina - Laboratório Associado, Escola Superior de Biotecnologia, Rua Diogo Botelho 1327, \\ 4169-005, Porto, Portugal \\ ${ }^{\mathrm{d}}$ Instituto Politécnico de Coimbra, ISEC, DEQB, Rua Pedro Nunes, Quinta da Nora, 3030-199, Coimbra, Portugal \\ e Instituto de Investigação Aplicada, Laboratório SiSus, Rua Pedro Nunes, Quinta da Nora, 3030-199, Coimbra, Portugal
}

\section{A R T I C L E I N F O}

\section{Keywords:}

17 $\beta$-estradiol (E2)

$17 \alpha$-ethinylestradiol (EE2)

Sulfamethoxazole (SMX)

Aerobic granular sludge (AGS)

Biomass structural characterization

Multivariate statistical techniques

\begin{abstract}
A B S T R A C T
In this study, a sequencing batch reactor (SBR) with aerobic granular sludge (AGS) was operated with synthetic wastewater containing environmental relevant concentrations of 17 $\beta$-estradiol (E2), 17 $\alpha$-ethinylestradiol (EE2) and sulfamethoxazole (SMX). Despite the presence of the studied PhAC, the granular fraction clearly predominated TSS $_{\text {gran }}$ TSS ranging from 0.82 to 0.98 ) throughout the monitoring period, presenting aggregates with high organic fraction (VSS/TSS above 0.83 ) and good settling characteristics (SVI ranging from 15 to $39 \mathrm{~mL} /$ gTSS). A principal component analysis (PCA) with quantitative image analysis (QIA) based data allowed to distinguish the different operational periods, namely with mature granules (CONT), and the E2, EE2, and SMX feeding periods. It further revealed a positive relationship between the biomass density, sludge settling ability, overall and granular biomass contents, granulation properties, granular biomass fraction and large granules fraction and size. Moreover, a discriminant analysis (DA) allowed to successfully discriminate not only the different operational periods, mainly by using the floccular apparent density, granular stratification and contents data, but also the PhAC presence in samples. The filamentous bacteria contents, sludge settling properties, settling properties stability and granular stratification, structure and contents parameters were found to be crucial for that purpose.
\end{abstract}

\section{Introduction}

It is known that pharmaceutical active compounds (PhAC), namely 17 $\beta$-estradiol (E2), 17 $\alpha$-ethinylestradiol (EE2), and sulfamethoxazole (SMX), can inflow into wastewater treatment plants (WWTP) resulting from different sources, including human excretion, pills production, and Human and veterinary activities (Combalbert and Hernandez-Raquet, 2010; Nieto et al., 2007; Ting and Praveena, 2017). Indeed, E2, EE2, and SMX, have already received wide attention due to several ecosystem and human health impacts that their presence in the environment pose Leal et al., 2020b. The presence of such compounds in surface waters can be partially explained by their inefficient removal in full scale WWTP including conventional activated sludge (CAS) (Joss et al., 2006). In fact, the concentrations of several PhAC usually found in aquatic environments range from ng L ${ }^{-1}$ to $\mu \mathrm{g} \mathrm{L}^{-1}$ (Ebele et al., 2017), being also found in quite toxic concentrations in pharmaceutical industry wastewaters in a higher $\mathrm{mg} \mathrm{L}^{-1}$ range (Sanderson et al., 2004; Vergili and Sezin, 2017). Thus, this entire range of concentrations could be considered as environmentally relevant (Weltje and Sumpter, 2017).

Sequencing batch reactors using aerobic granular sludge (SBR-AGS) have already been used to treat troublesome wastewaters including petrochemical, pulp and paper, hypersaline, oily, sulfur-laden, fish canning, high strength organic and heavy metals rich effluents (Caluwé et al., 2017; Corsino et al., 2016; Farooqi and Basheer, 2017; Hamza et al., 2018; Paulo et al., 2021; Wei et al., 2017; Xiong et al., 2020; Xue et al., 2017). Regarding the particular case of PhAC, references can be

\footnotetext{
* Corresponding author.

E-mail address: daniela@deb.uminho.pt (D.P. Mesquita).
} 
Table 1

Operational phases of SBR-AGS.

\begin{tabular}{lll}
\hline Operational phase & Duration & PhAC operational strategies \\
\hline CONT & 49 days & Operation in absence of PhAC \\
E2 & 86 days & Feeding of E2 every other week \\
EE2 & 28 days & Feeding of EE2 every other week \\
SMX & 28 days & Feeding of SMX every other week \\
\hline
\end{tabular}

found in literature reporting AGS as suitable for the treatment of wastewaters containing E2, EE2, and SMX (Balest et al., 2008; Kang et al., 2018; Kent and Tay, 2019; Liu et al., 2019).

A number of references report that the control of AGS systems could be improved by the enlightenment of the aggregates structure, morphology and size (Cydzik-Kwiatkowska et al., 2013; Long et al., 2019; Rusanowska et al., 2019; Verawaty et al., 2013). Quantitative image analysis (QIA) has proven to be a suitable tool for the structural assessment of biological aggregates in WWTP, such as the identification of CAS dysfunctions, including viscous and filamentous bulking abnormalities, ferric chloride effect in the morphology and settleability of AS systems, among others (Asensi et al., 2019; Mesquita et al., 2011a, 2011b). QIA techniques have also been employed for monitoring anaerobic granular sludge systems (Costa et al., 2010) and more recently in assessing mature and stable AGS systems (Leal et al., 2020a). However, the effect of PhAC on the AGS structure and density is still poorly understood.

Due to the large amount of information provided by QIA, its combined use with chemometric techniques has become increasingly important in organizing and extracting relevant information from such comprehensive datasets. Thus, different multivariate statistical techniques, including cross-correlation (CC), principal component analysis (PCA), decision trees (DT), partial least squares regression (PLS), and discriminant analysis (DA), among others, were already successfully applied for a number of studies encompassing biological WWT systems monitoring (Amaral, 2003; Deepnarain et al., 2019; Kim et al., 2011; Leal et al., 2016; Mesquita et al., 2016).

Taking the above into consideration, the main objective of this work was to assess the effect of three different PhAC (E2, EE2, and SMX) on the biomass morphology and structure of an SBR-AGS system using QIA methodologies. Chemometric (PCA and DA) multivariate statistical techniques were employed as an early detection mechanism of possible system dysfunctions caused by the presence of the studied PhAC.

\section{Material and methods}

\subsection{Experimental setup}

In this work, a $5 \mathrm{~L}$ lab scale SBR, was operated at room temperature $\left(18-23^{\circ} \mathrm{C}\right.$ ) with AGS for the treatment of a synthetic effluent (De Kreuk et al., 2005) containing $1000 \mathrm{mg} \mathrm{COD} \mathrm{L}{ }^{-1}, 200 \mathrm{mg} \mathrm{NH}_{4}^{+}-\mathrm{N} \mathrm{L}^{-1}$ and 80 $\mathrm{mg} \mathrm{PO}_{4}^{3-}-\mathrm{P} \mathrm{L}^{-1}$. Each operational cycle lasted for $6 \mathrm{~h}$ encompassing 120 min of feeding, $232 \mathrm{~min}$ of aeration, $3 \mathrm{~min}$ of settling and $5 \mathrm{~min}$ of withdrawal, and a hydraulic retention time of $12 \mathrm{~h}$. Air was supplied at $7.50 \mathrm{~L} \mathrm{~min}^{-1}$ resulting in a superficial air velocity above $1.8 \mathrm{~cm} \mathrm{~s}^{-1}$ during the monitoring period.

The SBR-AGS was operated for 49 days in the absence of PhAC, acting as a control phase. The results of this control experiment (CONT) can be found elsewhere (Leal et al., 2020a). Three experiments were later conducted in the presence of E2 $\left(0.221 \mathrm{mg} \mathrm{L}^{-1}\right)$, EE2 $(0.278 \mathrm{mg}$ $\left.\mathrm{L}^{-1}\right)$, and SMX $\left(0.290 \mathrm{mg} \mathrm{L}^{-1}\right)$, dissolved in ethanol, to mimic pharmaceutical industry wastewaters (Mills et al., 2015). Each PhAC was fed every other week, at two separated times during the week, and possible system dysfunctions were evaluated. In each experiment, carried out sequentially in the same SBR, before the first day of PhAC addition, the reactor was operated for 22 days without PhAC for the AGS stabilization. All PhAC feeds were protected from light to minimize the compounds photodegradation. The main operational phases of the SBR-AGS are presented in Table 1.

\subsection{Chemical analysis}

The total and volatile suspended solids for the overall biomass (TSS $_{\text {total }}$ and $\mathrm{VSS}_{\text {total }}$ ), and floccular $\left(\mathrm{TSS}_{\mathrm{floc}}, \mathrm{VSS}_{\text {floc }}\right.$ ) and granular (TSS $_{\text {gran }}$, VSS $_{\text {gran }}$ ) fractions, as well as the sludge volume index at 5 $\left(\mathrm{SVI}_{5}\right)$ and $30 \mathrm{~min}\left(\mathrm{SVI}_{30}\right)$, were determined according to standard methods (APHA, 2017). The aggregates density (Dens.) was determined with Blue dextran by the method described by (Beun et al., 2002).

Chemical oxygen demand (COD), ammonium nitrogen $\left(\mathrm{N}-\mathrm{NH}_{4}^{+}\right)$, nitrite $\left(\mathrm{N}-\mathrm{NO}_{2}^{-}\right)$, nitrate $\left(\mathrm{N}-\mathrm{NO}_{3}^{-}\right)$and phosphorus $(\mathrm{P})$ concentrations were determined with Hach Lange cell tests (Hach Lange, Dusseldorf, Germany). The total inorganic nitrogen (TIN) concentration in the influent was assumed to be equal to the ammonium concentration, while the TIN in the effluent was determined as the sum of ammonia, nitrite, and nitrate concentrations.

The E2, EE2, and SMX chromatographic analysis of the synthetic feeding entering the reactor (INLET), was performed by a Shimadzu Corporation apparatus (Tokyo, Japan) consisting of an UHPLC (Nexera) with a multi-channel pump (LC-30 CE), an autosampler (SIL-30AC), an oven (CTO-20AC), a diode array detector (M-20A) and a system controller (CBM-20A) with built-in software (LabSolutions), according to (Fonseca et al., 2013; Quintelas et al., 2019). The INLET collected samples were centrifuged at $8000 \mathrm{~g}$ and filtered with $0.2 \mu \mathrm{m}$ filter prior to HPLC analysis. E2, EE2, and SMX (98\%) were acquired from Sigma Aldrich. Blue dextran was acquired from GE Healthcare Biosciences.

\subsection{Sludge sampling}

A volume of $600 \mathrm{~mL}$ of sludge was collected at mid-point depth in the reactor, in the beginning of the aeration phase to obtain homogeneous and representative biomass samples. The samples were kept under moderate agitation conditions to avoid settling and promote the mixture between the solid and liquid phases. A $500 \mu \mathrm{m}$ sieve was next employed to separate the granular and suspended (floccular) fractions according to (Leal et al., 2020a). For that purpose, $35 \mathrm{~mL}$ aliquots were used in the E2 experiments (initial granular TSS concentrations under $15 \mathrm{~g} \mathrm{~L}^{-1}$ ) and 10 $\mathrm{mL}$ aliquots were used for the EE2 and SMX experiments (initial granular TSS concentrations above $15 \mathrm{~g} \mathrm{~L}^{-1}$ ).

From the floccular fraction, aliquots of $10 \mu \mathrm{L}$ (in triplicate) were collected with a micropipette, with a sectioned tip to allow the larger aggregates to flow through, deposited onto a slide and let to air-dry, in accordance to (Leal et al., 2020a). Images were then acquired in an Olympus BX51 microscope (Olympus, Shinjuku, Japan) and in a Nikon Eclipse Ci-L (Nikon Corporation, Tokyo, Japan) in bright field at a total magnification of $40 \times$ for the CONT and E2 experiments and $100 \times$ for the EE2 and SMX experiments. A total of 150 images (50 image$\mathrm{s}$ /triplicate) were acquired resulting in a 12,000 flocs/sample average.

Regarding the granular fraction, the entire set of granules retained in the sieve, from the 10 and $35 \mathrm{~mL}$ aliquots, were deposited in a Petri dish and acquired in an Olympus SZ 40 stereomicroscope (Olympus, Shinjuku, Japan) at total magnification of $15 \times$. For the case of the SMX experiment, a Leica S8AP0 stereomicroscope (Leica, Wetzlar, Germany) was used under a total magnification of $16 \times$. This resulted in an average of 840 granules/sample for the $35 \mathrm{~mL}$ aliquots and 394 granules/sample for the $10 \mathrm{~mL}$ aliquots.

\subsection{QIA methodology}

Two previously developed QIA routines were run on the acquired images in Matlab 7.8 (The Mathworks, Natick, MA) for the structural and morphological characterization of the granular and floccular fractions, respectively. A detailed description of these routines can be found elsewhere (Amaral, 2003; Deepnarain et al., 2019; Leal et al., 2016; 
a)

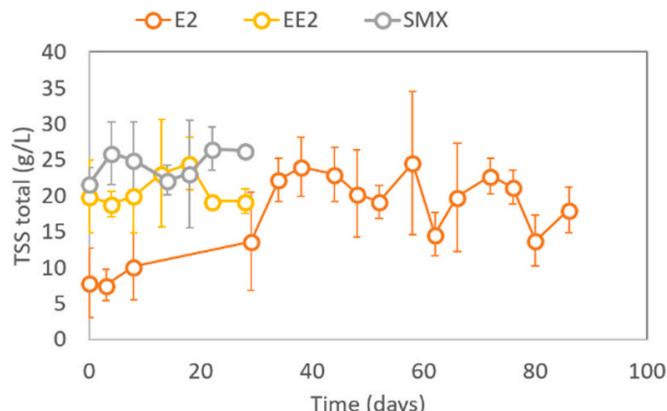

c)

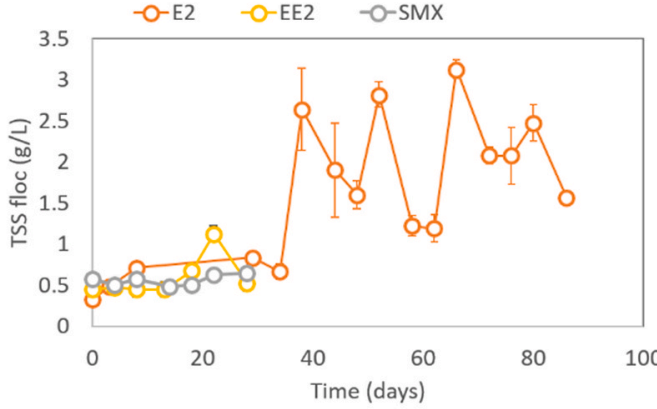

e)

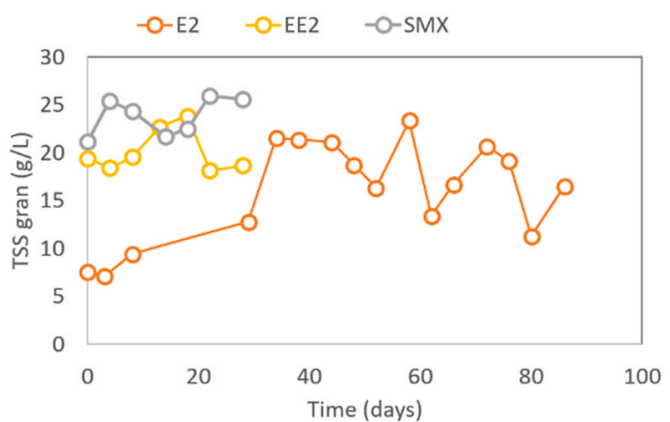

g)

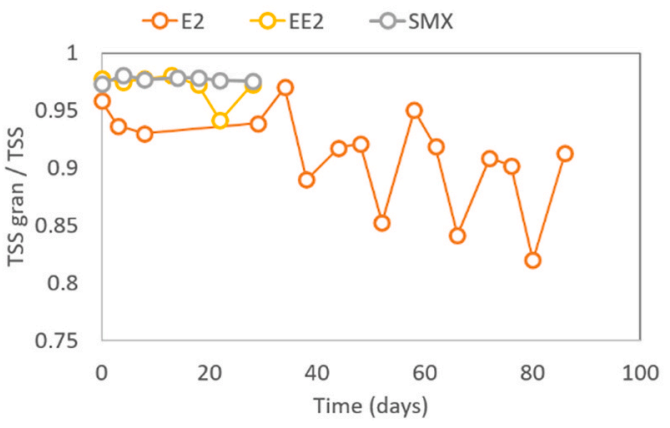

b)
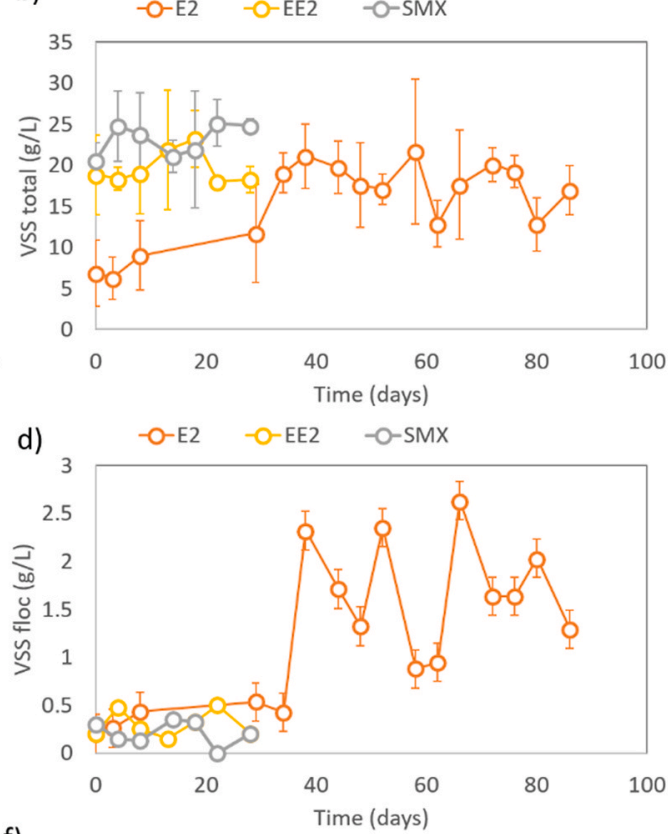

f)

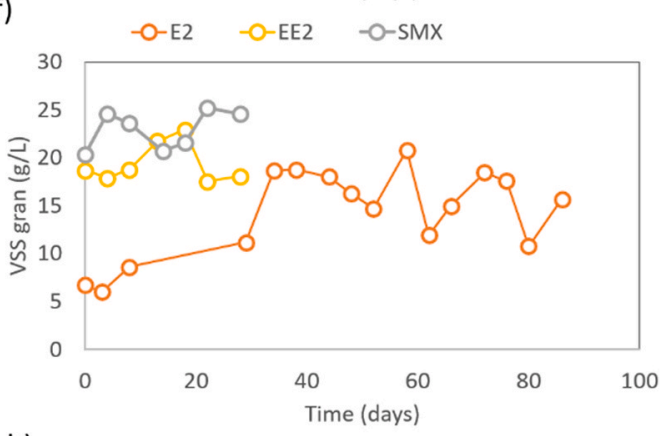

h)

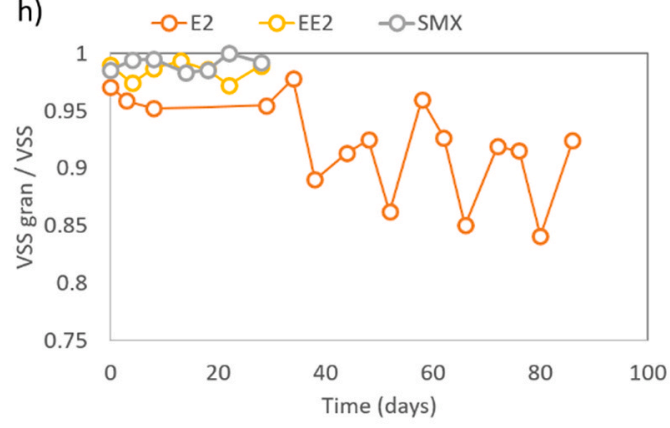

i) $\quad-O-E 2 \quad-O-E E 2 \quad-O-S M X$

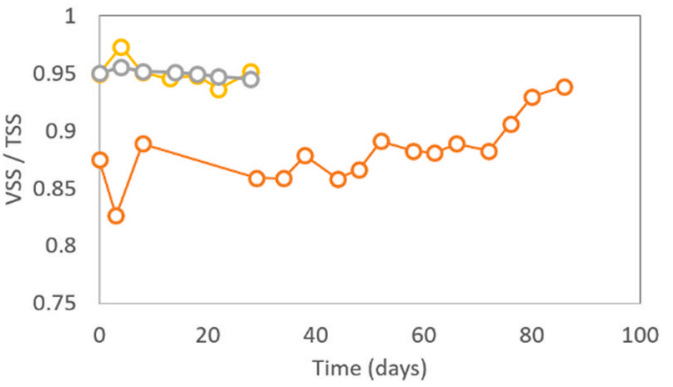

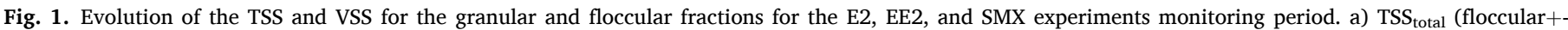
granular), b) VSS total (floccular+granular), c) TSS floc, d) VSS floc, e) TSS gran, f) VSS gran, g) TSS gran $/$ TSS $_{\text {total }}$, h) VSS gran $_{\text {r VSS }}$ total, and i) VSS/TSS. 

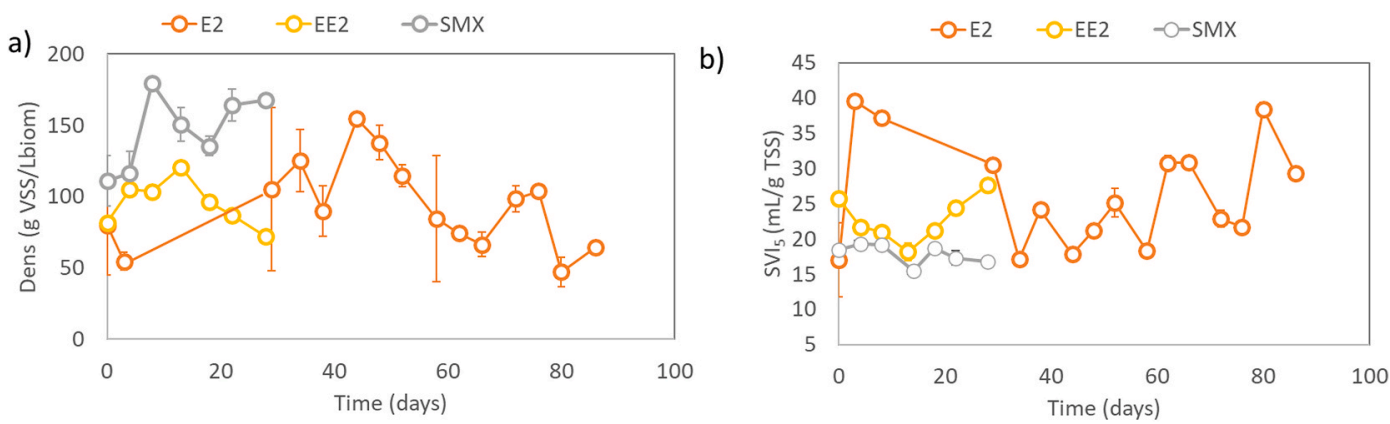

c)

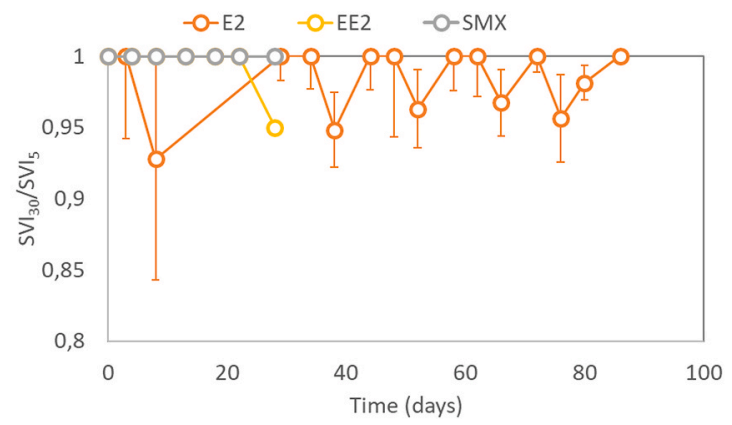

Fig. 2. Evolution of the AGS density and settling properties for the E2, EE2, and SMX experiments monitoring period. a) Density, b) $S V I_{5}$ and c) $\mathrm{SVI}_{30} / \mathrm{SVI}_{5}$.

a)
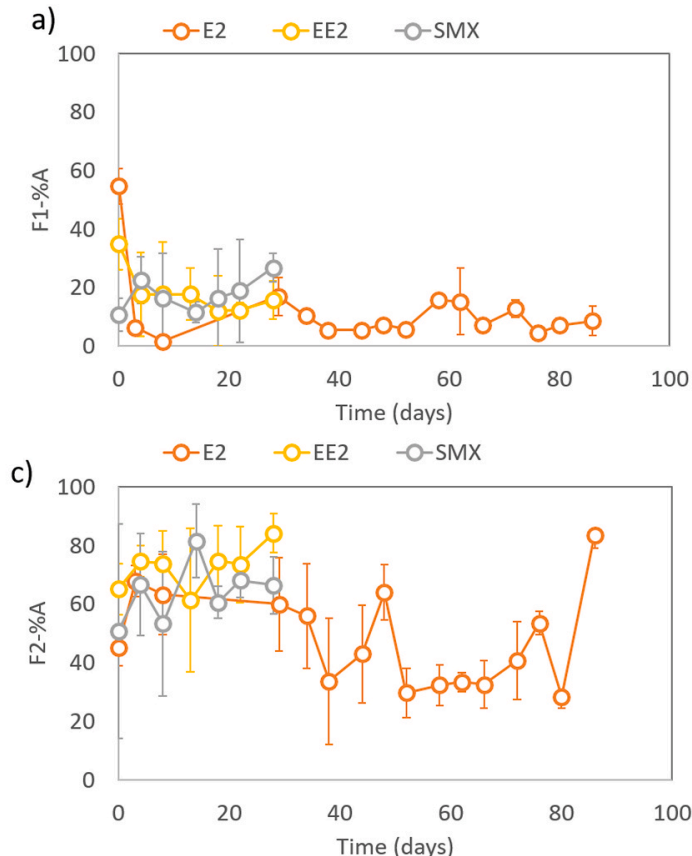

e)

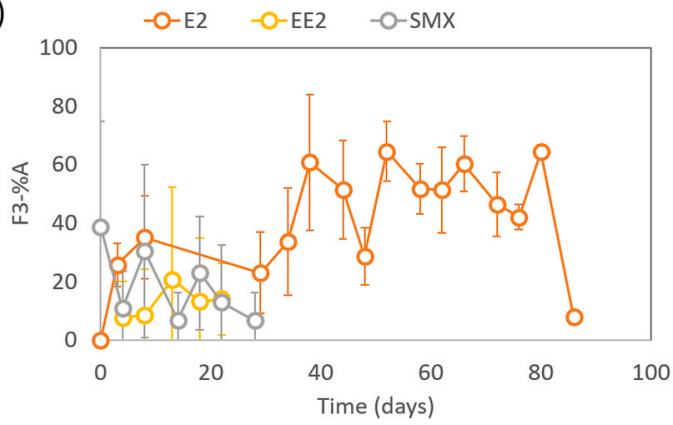

b)

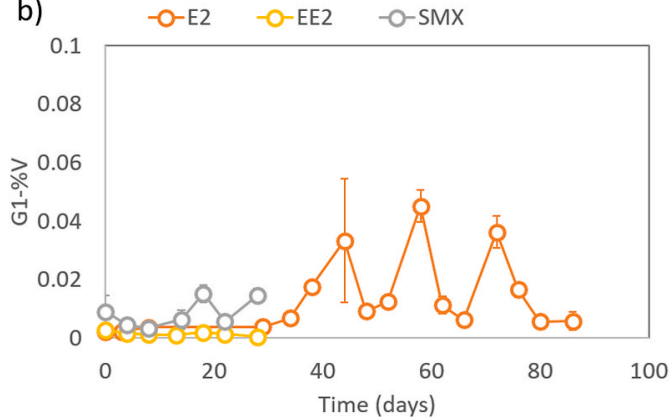

d)

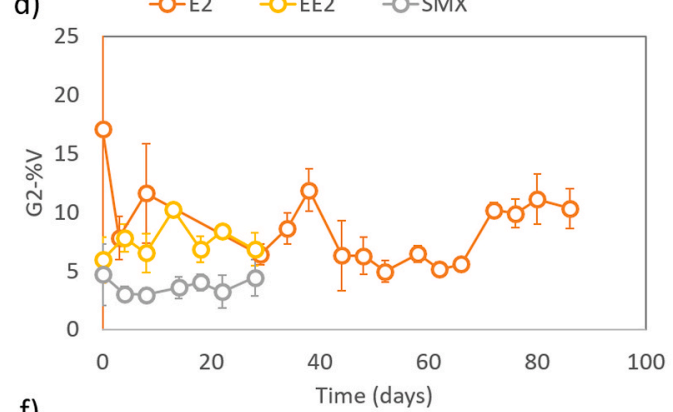

f)

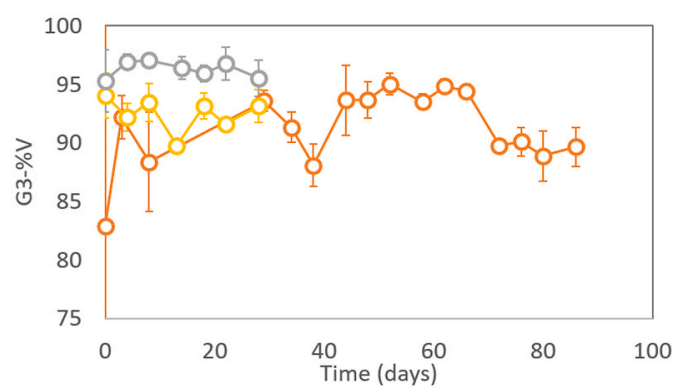

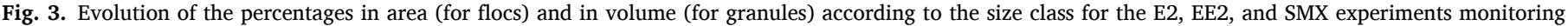
period. a) F1-\%A, b) G1-\%V, c) F2-\%A, d) G2-\%V, e) F3-\%A and f) G3-\%V. 
a)

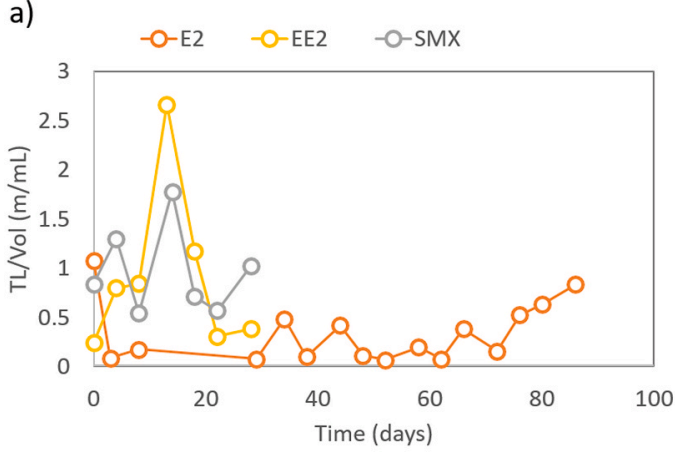

c)

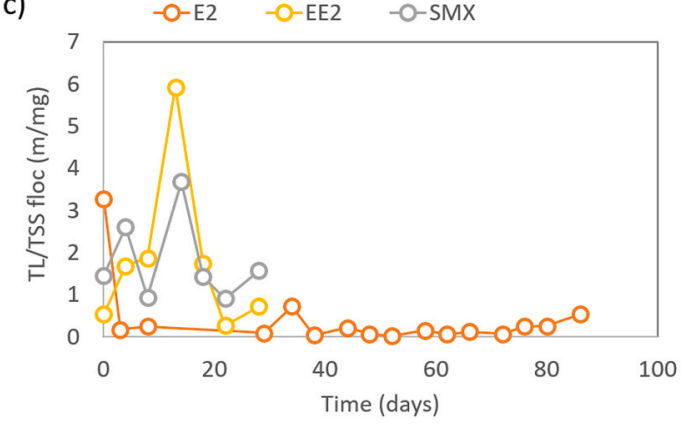

b)

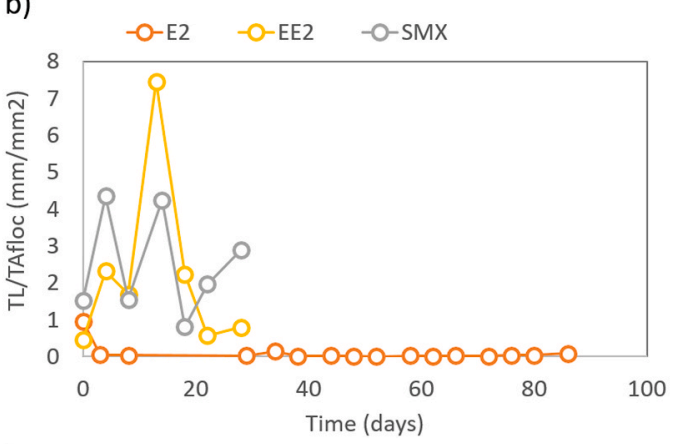

d)

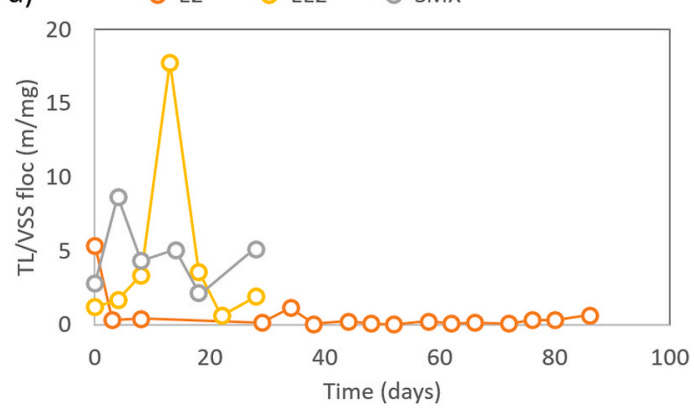

Fig. 4. Evolution of filamentous bacteria contents during the monitoring period a) TL b) TL/TA floc c) TL/TSS floc $d$ ) $T L / V S S_{\text {floc }}$.

Mesquita et al., 2016).

The collected structural and morphological parameters were the aggregate's projected area (Area or A, for flocs), projected volume (Vol. or $V$, for granules), equivalent diameter (Deq or $D$ ), length $(L)$, width $(W)$, robustness (Rob.), eccentricity (Ecc.) and convexity (Conv.), among others, as well as the total flocs area (TA) per volume and total granules volume (TV) per volume. Furthermore, the total filamentous bacteria (protruding and free filaments) length per volume (TL), total filaments length per total flocs area $\left(T L / T A_{f l o c}\right.$ ), total filaments length per TSS (TL/ $\left.T S S_{f l o c}\right)$, and total filaments length per VSS $\left(T L / V S S_{f l o c}\right)$ were also assessed. The main parameters determined for the suspended (floccular) and granular sludge fractions can be found in section 1 of the supplementary material. A detailed description of these parameters can also be found in (Leal et al., 2020a).

Given their wide size stratification, the flocs were further divided into three classes considering its Deq: F1 $(<25 \mu \mathrm{m}), \mathrm{F} 2(25-250 \mu \mathrm{m})$ and F3 $(>250 \mu \mathrm{m})$. For the same reason, three size classes were also considered for the granules, again based on the Deq: G1 $(<0.25 \mathrm{~mm})$; G2 $(0.25-2.5 \mathrm{~mm})$ and $\mathrm{G} 3(>2.5 \mathrm{~mm})$. The number percentage $(\% \mathrm{Nb})$ for both flocs and granules, area percentage (\%A) for the flocs, and volume percentage $(\% \mathrm{~V})$ for the granules, were also determined for each size class in order to evaluate the dominant size class. The chosen parameters, and size classes, have already been proven to be useful in mature AGS monitoring (Leal et al., 2020a).

\subsection{Principal component analysis}

In the current study, principal component analysis (PCA) was performed for the ensemble CONT, E2, EE2, and SMX experiments regarding the SBR-AGS physicochemical parameters (with and without density) and/or the main QIA morphological parameters of both granular and floccular AGS fractions. The main objective of the employed PCA focused on the establishment of the key interrelationships between, and within, the physicochemical and morphological parameters, as well as with the found clusters.

\subsection{Discriminant analysis}

Likewise PCA, discriminant analysis (DA) was performed for the ensemble CONT, E2, EE2, and SMX experiments regarding the SBR physicochemical parameters (with and without density) and/or the main QIA morphological parameters of both granular and floccular AGS fractions. The main objective of the employed DA focused on selecting the best orthogonal combinations of the physicochemical and/or morphological parameters, for the separation of each experiment group.

Matlab 7.8 (The Mathworks, Inc. Natick) was used to perform both PCA and DA. A total of 34 observations and 140 variables were employed for both analyses when the sludge density was included, whereas 28 observations and 139 variables were employed otherwise. Ensemble and separate PCA and DA were performed for the floccular and granular fractions, as well as for the sludge physicochemical and structural properties.

\section{Results and discussion}

\subsection{Operational parameters}

The average values of the PhAC concentrations entering the reactor (INLET) were similar $\left(0.221,0.278\right.$, and $0.290 \mathrm{mg} \mathrm{L}^{-1}$ for E2, EE2, and SMX respectively). The chemical oxygen demand (COD) removal efficiency was above $91 \%$, throughout the experiments, whereas the total inorganic nitrogen removal (TIN) varied from $84 \%$ to $100 \%$. On the other hand, the total phosphorous (TP) removal was quite poor during all experiments, and never surpassing $42.6 \%$ in all cases. More data on the performance of the SBR-AGS in terms of COD, TIN and TP removal efficiencies can be found in section 2 of the supplementary material.

\subsection{Overall biomass characterization}

The SBR-AGS biomass characterization throughout the monitoring period, in terms of the TSS and VSS, for the granular and floccular fractions, is presented in Fig. 1 for the studied PhAC.

The total VSS (Fig. 1b) in the E2 experiment presented an average of $15.6( \pm 5.0) \mathrm{g} \mathrm{L}^{-1}$ and the total TSS (Fig. 1a) an average of $17.7( \pm 5.7) \mathrm{g}$ 

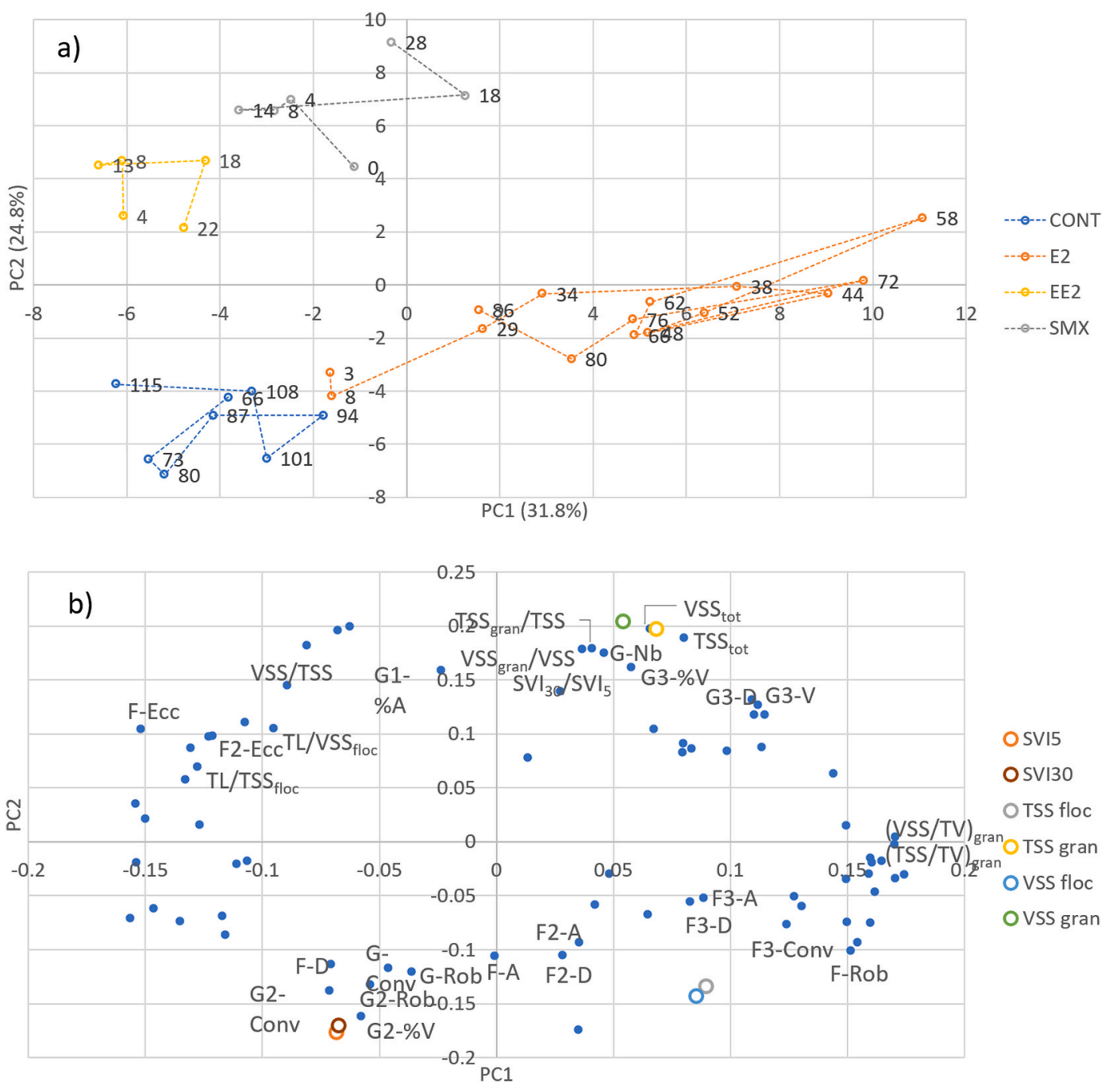

Fig. 5. PCA with the mature AGS experiment data. a) Operational periods and b) AGS structure, contents and settleability.

$\mathrm{L}^{-1}$, resulting in a VSS/TSS ratio of $0.88( \pm 0.03)$. With respect to the EE2 experiment, the total VSS averaged $19.7( \pm 2.0) \mathrm{g} \mathrm{L}^{-1}$ and the total TSS $20.7( \pm 2.2) \mathrm{g} \mathrm{L}^{-1}$, resulting in a VSS/TSS ratio (Fig. 1i) of 0.95 $( \pm 0.01)$. Slightly higher contents were obtained for the SMX experiment, with the total VSS averaging $23.2( \pm 1.9) \mathrm{g} \mathrm{L}^{-1}$ and the total TSS averaging $24.4( \pm 2.0) \mathrm{g} \mathrm{L}^{-1}$, resulting in a VSS/TSS ratio of 0.95 $( \pm 0.00)$. The suspended solids (both VSS and TSS) contents at the beginning of the E2 experiment were quite lower than for the EE2 and SMX experiments due to the fact that the experiments were performed sequentially (E2 followed by EE2 and by SMX). Indeed, the reactor biomass at the end of each experiment, following a 22 days period without PhAC for AGS stabilization, was used for the subsequent experiment. The obtained solids contents were found to be similar to a hybrid granular sludge system operating under low hydraulic pressure (Lang et al., 2015), whereas similar VSS/TSS values were obtained in the start-up period of a pilot scale granular sludge reactor treating low strength wastewaters (Isanta et al., 2012).

Both solids (TSS and VSS) contents at the beginning of the E2 experiment were quite lower than for the EE2 and SMX experiments. The VSS/TSS ratio allowed establishing a high, and relatively constant, organic fraction of the aggregates, for the EE2 and SMX experiments. On the other hand, regarding the E2 experiment this ratio increased during the monitoring period until reaching similar values to the EE2 experiment in the end.

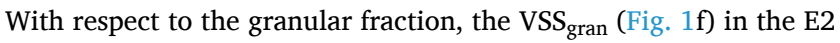

experiment averaged $14.3( \pm 4.6) \mathrm{g} \mathrm{L}^{-1}$ and the $\mathrm{TSS}_{\text {gran }}$ (Fig. 1e) 16.1 $( \pm 5.2) \mathrm{g} \mathrm{L}^{-1}$. These values increased to $19.4( \pm 2.1) \mathrm{g} \mathrm{L}^{-1}$ for the $\mathrm{VSS}_{\text {gran }}$ and to $20.1( \pm 2.2) \mathrm{g} \mathrm{L}^{-1}$ for the TSS gran, regarding the EE2 experiment, and to $22.9( \pm 2.0) \mathrm{g} \mathrm{L}^{-1}$ to $23.8( \pm 2.0) \mathrm{g} \mathrm{L}^{-1}$, respectively, for the SMX experiment. The granular fraction behavior, given its clear predominance in the total biomass (discussed below), was found to mimic the total solids contents.

On the other hand, for the floccular fraction of the biomass, the

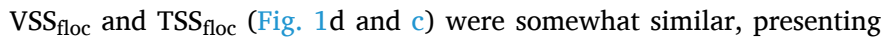
lower values (around $3 \%$ of the TSS and VSS of total biomass (flocs + granules)) when compared to the granular fraction throughout the monitoring period of the EE2 and SMX experiments, and up until day 34 of the E2 experiment. From that day onwards they sharply increased and become oscillating for this PhAC varying from 4 to $18 \%$ of the TSS of total biomass (flocs + granules).

Considering the total biomass (flocs + granules), it was evident that, for all experiments, the granular fraction clearly predominated (average values above $90 \%$ for all experiments), being slightly higher for the EE2 and SMX experiments, than in the E2 experiment where a small decrease could be found. These results might indicate that the E2 caused a more pronounced effect in the AGS system compared with the other studied $\mathrm{PhAC}$ (despite the $\mathrm{SVI}_{30} / \mathrm{SVI}_{5}$ value of 1 ) for this experiment (discussed below).

The SBR-AGS biomass settling characteristics $\left(\mathrm{SVI}_{5}\right.$ and $\left.\mathrm{SVI}_{30} / \mathrm{SVI}_{5}\right)$ and density, for the studied PhAC monitoring periods, are presented in 

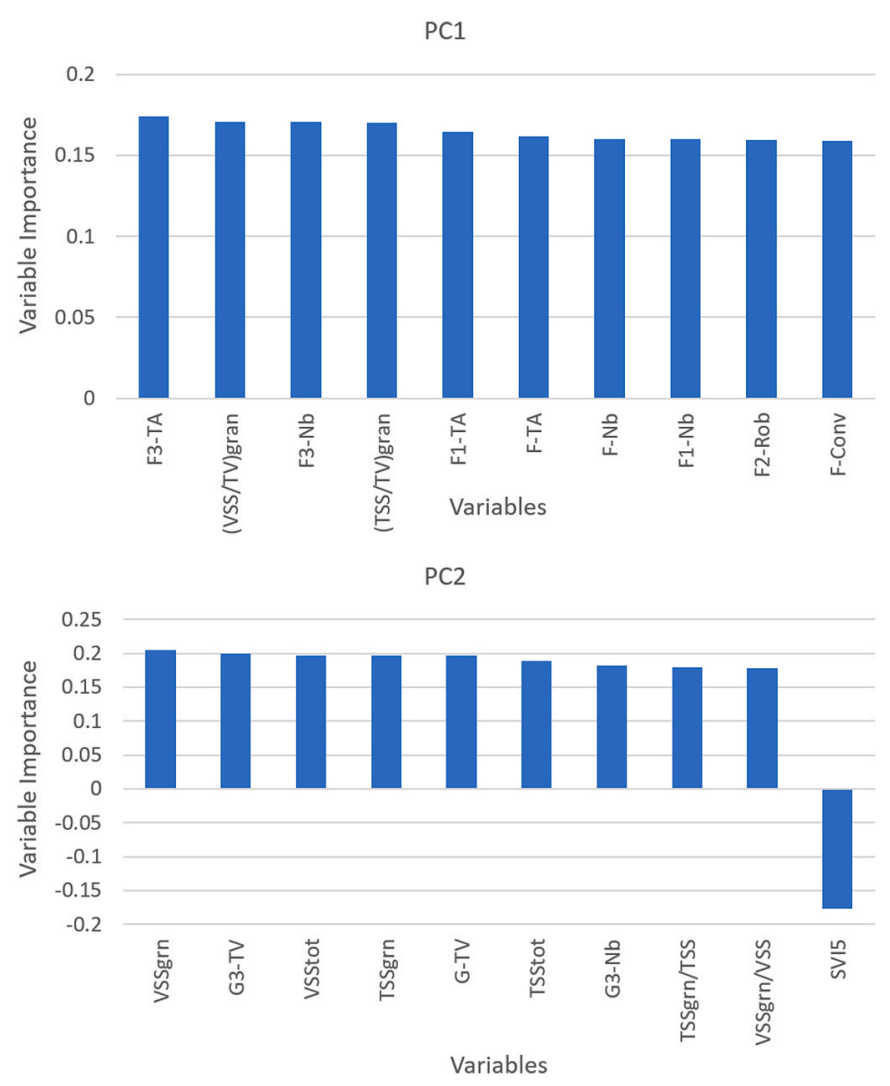

Fig. 6. Variable importance for PC1 and PC2, regarding the PCA analysis of Fig. 5.

Fig. 2.

The E2 experiment biomass density (Fig. 2a) averaged $93.4( \pm 30.9)$ $\mathrm{g}$ VSS L ${ }^{-1}$ biomass, while for the EE2 averaged $95.1( \pm 16.4) \mathrm{g} \mathrm{VSS} \mathrm{L}^{-1}$ biomass. Regarding the SMX experiment, the biomass density was higher than for the estrogens, showing an increasing trend throughout the monitoring period, and averaging $146.4( \pm 26.4) \mathrm{g} \mathrm{VSS} \mathrm{L}^{-1}$ biomass. The obtained lower density values are within the published studies in the literature for AGS pulsed aerated operation and granules disintegration in long term AGS systems operation (Carrera et al., 2019; Yuan et al., 2017). On the other hand, the higher values are within the range of continuous AGS systems operation when performing nitrification and simultaneous biodegradation of p-nitrophenol (Jemaat et al., 2013).

The E2 experiment $\mathrm{SVI}_{5}$ (Fig. 2b) value averaged $26.4( \pm 7.7) \mathrm{mL} \mathrm{g}^{-1}$ TSS, the EE2 averaged $22.8( \pm 3.2) \mathrm{mL} \mathrm{g}^{-1}$ TSS, whilst the SMX presented a lower value of $17.9( \pm 1.4) \mathrm{mL} \mathrm{g}^{-1}$ TSS. In all cases, the presented values, and variation range, allow to infer, globally, a biomass with good settleability characteristics. In fact, similar SVI results have already been found for AGS in SBR systems, during the treatment of sulfonamides, including SMX and tetracyclines (Liu et al, 2006, 2019; Mendes Barros et al., 2021). Taking into consideration that possible AGS systems dysfunctions can also be evaluated by monitoring the $\mathrm{SVI}_{30} / \mathrm{SVI}_{5}$ ratio (Fig. 2c), a quite stable system was observed regarding the EE2 and SMX experiments presenting a constant value of 1 (with exception of the last day of EE2 experiment resulting in most of the EE2 data points overlapped by SMX data points in Fig. 2c) and a slight instability for the E2 (ranging from 0.93 to 1 and averaging $0.98 \pm 0.02$ ).

Considering the above results, the EE2 presence did not strongly affected the high, and relatively constant, organic fraction of the aggregates, nor the granular fraction which clearly predominated. On the other hand, the biomass settling ability and aggregates' density decreased from mid-point in the experiment onwards. The E2 presence led to the most apparent effect in the SBR-AGS biomass with a slight decrease in the organic fraction, biomass settling ability and aggregates' density and a smaller final granular biomass contents, despite the increase in the aggregates organic fraction. On the other hand, the SMX presence led to the less pronounced effect, not strongly affected the high organic fraction of the aggregates, nor the clearly predominant granular fraction. Furthermore, the SMX experiment led to an increase on the sludge density, while maintaining a high settleability, and to the larger final granular biomass contents.

\subsection{AGS structural characterization}

The evolution of the percentages in area (for flocs) and in volume (for granules), according to the size class, in the studied PhAC experiments is presented in Fig. 3. Analyzing this figure, the intermediate F2 flocs $(25-250 \mu \mathrm{m})$ class increased and predominated throughout the entire EE2 and SMX feeding periods (c), averaging 72.5\% ( $\pm 7.4 \%)$ and $64.0 \%$ $( \pm 10.3 \%)$ respectively. However, a difference could be found regarding the second most representative fractions, namely the small F1 flocs (Fig. 3a) $(<25 \mu \mathrm{m})$ averaging $18.3 \%( \pm 7.7 \%)$ for the EE2 experiment, and both the large F3 (Fig. 3e) $(>250 \mu \mathrm{m})(18.4 \% \pm 12.5 \%)$ and intermediate $\mathrm{F} 2(17.6 \% \pm 5.8 \%)$ flocs for the SMX experiment. With respect to the $\mathrm{E} 2$ experiment, the intermediate $\mathrm{F} 2$ class predominated until day 34 , and in days 48,76 and 86 , averaging $48.0 \%( \pm 16.5 \%)$, whereas the large F3 class predominated from day 38 onwards averaging $42.6 \%$ ( $\pm 18.3 \%$ ) (last day excluded).

Furthermore, it could be established that the E2 experiment, apart from the first and last days, presented a higher larger flocs fraction, and lower intermediate and smaller flocs fractions, than the EE2 and SMX experiments. These results could also partially explain the $\mathrm{SVI}_{5}$ and $\mathrm{SVI}_{30}$ values for these periods in the E2 experiment.

Likewise the flocs area percentage, the granular volume percentage has also been found relevant in assessing AGS systems (Leal et al., 2020a), further corroborated in the present study. In all experiments the large G3 (Fig. 3f) (>2.5 mm) granules clearly predominated throughout the monitoring period, averaging $92.5 \%( \pm 1.4 \%), 91.3 \pm(3.3 \%)$ and $96.3 \%( \pm 0.7 \%)$ for the EE2, E2, and SMX, respectively. The remaining granules mostly belong to the intermediate G2 (d) $(0.25-2.5 \mathrm{~mm})$ class, averaging $7.5 \% \pm(1.4 \%), 8.2 \%$ ( $\pm 2.5 \%$ ) (first day excluded) and $3.7 \%$ $( \pm 0.7 \%)$ for the EE2, E2, and SMX, respectively. In all experiments the small granules (G1) (Fig. 3b) $(<0.25 \mathrm{~mm}$ ) never surpassed $0.1 \%$.

No significant differences were found between the granular fractions during the E2 and EE2 experiments, both presenting slightly smaller granules than the SMX experiment.

The filamentous bacteria presence in the reactor was evaluated through the determination of the TL, TL/TA floc, TL/TSS floc and TL/ $\mathrm{VSS}_{\text {floc }}$ during the monitoring period (Fig. 4). In all cases, the values of these parameters were found to be quite lower that the set of values for bulking conditions in conventional activated sludge (CAS) $\left(20 \mathrm{~m} \mathrm{~mL}^{-1}\right.$ for TL, $15 \mathrm{~mm} \mathrm{~mm}^{-2}$ for TL/TA floc and $7 \mathrm{~m} \mathrm{mg}^{-1}$ for TL/TSS floc according to (Mesquita et al., 2008). The lowest values were presented by the E2 experiment and even for the EE2 experiment filamentous peak, at day 13 , no bulking conditions could be inferred by the presented values. Analyzing the obtained results, the EE2 and SMX experiments presented very similar and slightly higher values than the E2 experiment.

Considering the above results, the studied PhAC presence did not strongly affected the (predominantly large) granular structure and, despite the EE2 peak at day 13, nor the (low) filamentous contents. On the other hand, a slight increasing trend for the intermediate flocs could be found by the EE2 and SMX presence, whereas a shift towards the larger flocs could be found for the $\mathrm{E} 2$ experiment mid-point into the experiment which, again, led to the most apparent effect in the SBR-AGS biomass.

\subsection{Principal component analysis}

The results of the main performed PCA for the PhAC (E2, EE2, and SMX) dataset, including the control (CONT) experiment when feasible, 

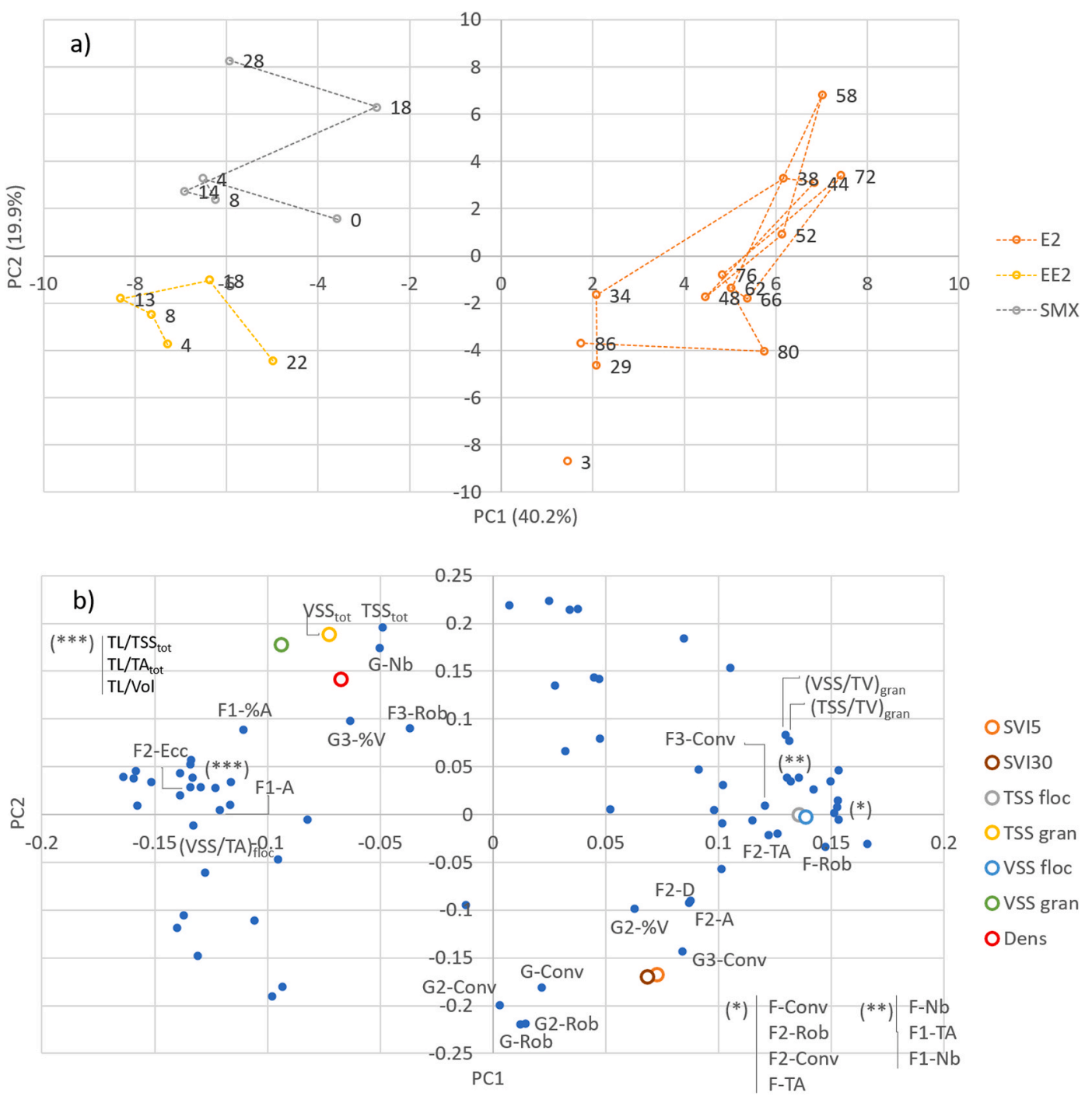

Fig. 7. PCA with the AGS physical and QIA data including density. a) Operational periods and b) AGS physical and settling properties.

is next addressed. The PCA addressed the SBR-AGS biomass (filamentous, suspended and granular) structure (assessed by QIA), contents and settleability, and was performed both with and without the biomass density, since no data regarding this parameter could be obtained for the control experiment.

The PCA performed with the inclusion of the mature AGS experiment data, thus excluding the biomass density, is presented in Fig. 5. Solely PC1 and PC2 were used in this analysis, given that PC3 (explaining $10.6 \%$ of the original dataset variance) did not present a significant improvement in the obtained clusters distinction.

The results presented in Fig. 5a revealed four naturally occurring clusters, corresponding to the control experiment with mature granules (CONT) and in the presence of E2, EE2, and SMX, through the use of PC1 and PC2 (explaining $31.8 \%$ and $24.8 \%$ of the original dataset variance, respectively). The E2 experiment was characterized by presenting positive PC1 values, with exception of the initial period, and slightly negative PC2 values. On the other hand, positive values for PC2 could be inferred for the SMX and EE2 operational periods. Moreover, both operational periods showed also mainly negative PC1 values. In fact, these results could be explained by a somewhat similar biomass behavior in terms of morphology and structure during both operational periods. In addition, in the bottom left quadrant, the CONT experiment was characterized by negative values for both PC1 and PC2.

With respect to the variables importance shown in Fig. 6, it should be stressed that PC1 was positively influenced by the large and total flocs contents (F3-TA, F3-Nb, F-TA and F-Nb) and the granules apparent density ((VSS/TV) gran and (TSS/TV) gran). These values can be correlated to the high flocs contents and higher granules apparent density (data not shown) found for the E2 experiment.

On the other hand, the PC2 was positively influenced by the overall and granular biomass TSS $_{\text {total, }}, \mathrm{VSS}_{\text {total }}, \mathrm{TSS}_{\text {gran, }} \mathrm{VSS}_{\text {gran }}$ and G-TV) and large granules (G3-TV and G3-Nb) contents and negatively influenced by the $\mathrm{SVI}_{5}$. These results are in accordance with the biomass and large granules values during the control experiment with mature granules (the lowest among all experiments) and the $\mathrm{SVI}_{5}$ values (the highest among all experiments). In addition, the difference between the SMX and EE2 clusters could be explained by the SMX experiment higher biomass and granules contents TSS $_{\text {total, }}$ VSS $S_{\text {total }}$, TSS $_{\text {gran }}$ and VSS $_{\text {gran }}$ ), higher granules apparent density ((VSS/TV) gran and (TSS/TV)gran) and slightly lower $\mathrm{SVI}_{5}$ values. More data regarding the granules apparent density in the CONT, E2, EE2 and SMX experiments, as well as the $\mathrm{SVI}_{5}$ in the CONT experiment, can be found in section 3 of the supplementary material.

Regarding the AGS structure, contents and settling properties, presented in Fig. $5 \mathrm{~b}$, the $\mathrm{SVI}_{5}$ and $\mathrm{SVI}_{30}$ were situated opposite to the granular biomass (TSS $_{\text {gran }}$ and VSS gran $_{\text {) }}$ contents. Furthermore, the results showed a close relationship of the SVI with the total flocs size (F-D and F-A, quite dependent on the F1 values), intermediate granules 

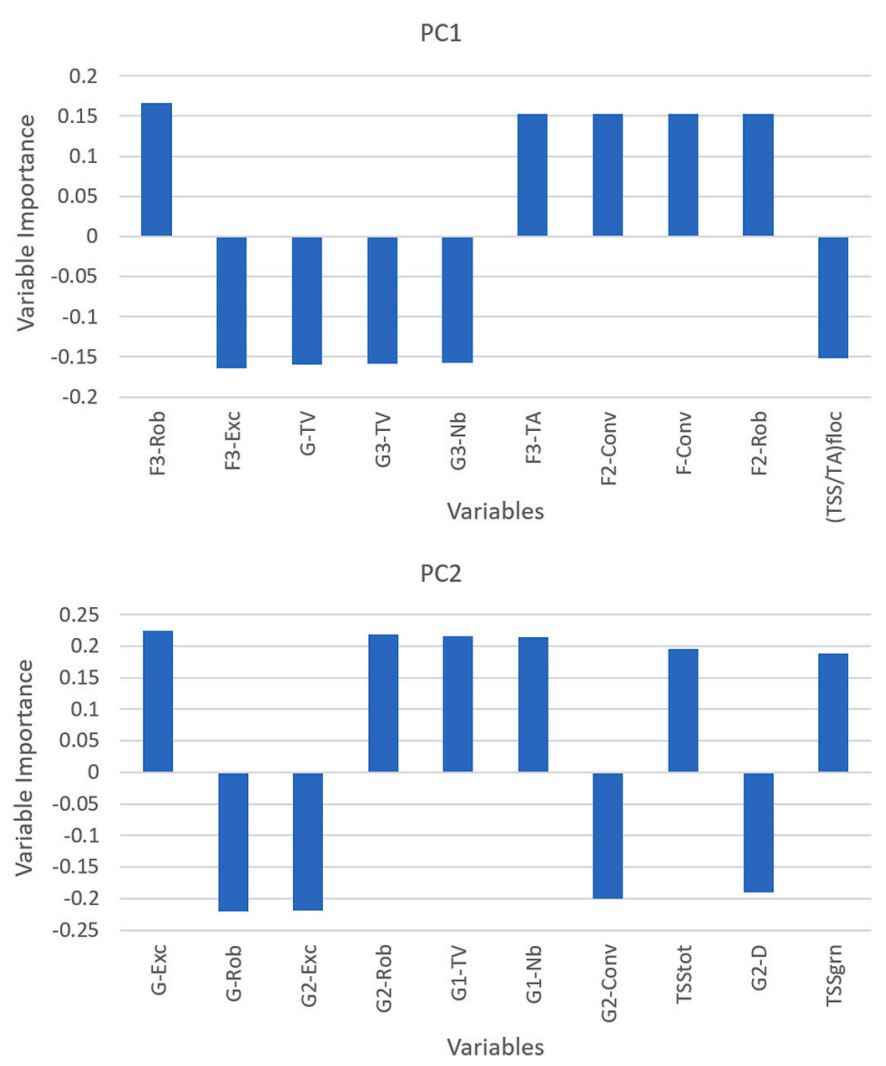

Fig. 8. Variable importance for PC1 and PC2, regarding the PCA analysis of Fig. 7.

fraction (G2-\%V, opposite to $\mathrm{G} 3-\% \mathrm{~V})$ and overall and intermediate granules regularity (G-Rob, G-Conv, G2-Rob and G2-Conv). In accordance, an opposite behavior was found between these parameters and the granular biomass TSS $_{\text {gran }}$ and VSS $_{\text {gran }}$ ) contents.

On the other hand, the granular biomass contents were found to show a close relationship with the overall biomass (TSS tot $_{\text {and }} \mathrm{VSS}_{\text {tot }}$ ), granulation properties $\left(\mathrm{SVI}_{30} / \mathrm{SVI}_{5}\right.$ ratio), granular biomass fraction (TSS $_{\text {gran }} / \mathrm{TSS}$ and $\mathrm{VSS}_{\text {gran }} / \mathrm{VSS}$ ), granules (G-Nb) contents and large granules fraction (G3-\%V) and size (G3-V and G3-D). In accordance, an opposite behavior was found between these parameters and the SVI values.

With respect to the floccular biomass (TSS floc $_{\text {and }}$ VSS floc $_{\text {), the results }}$ showed a close relationship with the intermediate and large flocs size (F2-A, F2-D, F3-A and F3-D) and regularity (F-Rob and F3-Conv). On the other hand, an opposite behavior was found regarding the biomass organic fraction (VSS/TSS ratio), filamentous bacteria contents per floccular biomass (TL/TSS floc $_{\text {and }} \mathrm{TL} / \mathrm{VSS}_{\text {floc }}$ ), overall and intermediate flocs irregularity (F-Ecc and F2-Ecc) and small flocs fraction (F1-\%A).

Aiming to understand the biomass density (Dens.) relationship with the AGS morphology and structure, a second PCA was performed, including this parameter in the dataset (and excluding the CONT samples that presented no data for this parameter). The main results of the second PCA are presented in Fig. 7. Solely PC1 and PC2 were used in this analysis, given that PC3 (explaining $7.4 \%$ of the original dataset variance) did not present a significant improvement in the obtained clusters distinction.

Analyzing Fig. 7a three naturally occurring clusters can be clearly found, representing the three (E2, EE2, and SMX) experiments, by the use of PC1 and PC2 (explaining, respectively, $40.2 \%$ and $19.9 \%$ of the original dataset variance). The E2 experiment is characterized by positive PC1 values, contrary to the EE2 and SMX. Regarding the EE2 experiment, both PC were found to be negative, whereas the SMX experiment presented negative PC1 values but positive PC2 values. Again, the EE2 and SMX experiments are not too far apart in the PCA analysis, explained by a somewhat similar biomass behavior in terms of morphology and structure during both operational periods.

Regarding the variables importance, shown in Fig. 8, the most relevant variables for PC1 were found to be the large, intermediate and total flocs regularity (F3-Rob, F2-Rob, F2-Conv and F-Conv) and large flocs contents (F3-TA), with a positive influence. On the other hand, with a negative influence, the most important are the total and large granules contents (G-TV, G3-TV and G3-Nb) and the flocs apparent density ((TSS/ $\mathrm{TA})_{\text {floc }}$ ). These results confirm, and add, to the previous analysis, and can be related to the high flocs contents (at the expense of the granules contents) and overall flocs regularity (though presenting lower apparent density) in the E2 experiment (data not shown).

Regarding PC2, the most important variables were found to be the total and small granules contents TSS $_{\text {total }}$, TSS $_{\text {gran }}$, G1-TV and G1-Nb), with a positive influence. In fact, these results are in accordance with the presence of significant small granules contents in the SMX and second part of the E2 experiments. Although somewhat conflicting, the total and intermediate granules structure (G-Ecc, G-Rob, G2-Ecc, G2Rob and G2-Conv) could be also found important for PC2. Interestingly, with the absence of the CONT samples, the biomass settling ability and the large granules contents lost some significance regarding the most important PC.

Taking into consideration Fig. 7b, some interesting results can be inferred, namely regarding the biomass density, which can be positively related to the granular biomass contents TSS $_{\text {gran }}$, VSS $_{\text {gran }}$ ) and negatively to the $\mathrm{SVI}_{5}$ and $\mathrm{SVI}_{30}$. The granular biomass contents and overall density correlate with the overall biomass TSS $_{\text {total }}$ and VSS $_{\text {total }}$ ) and

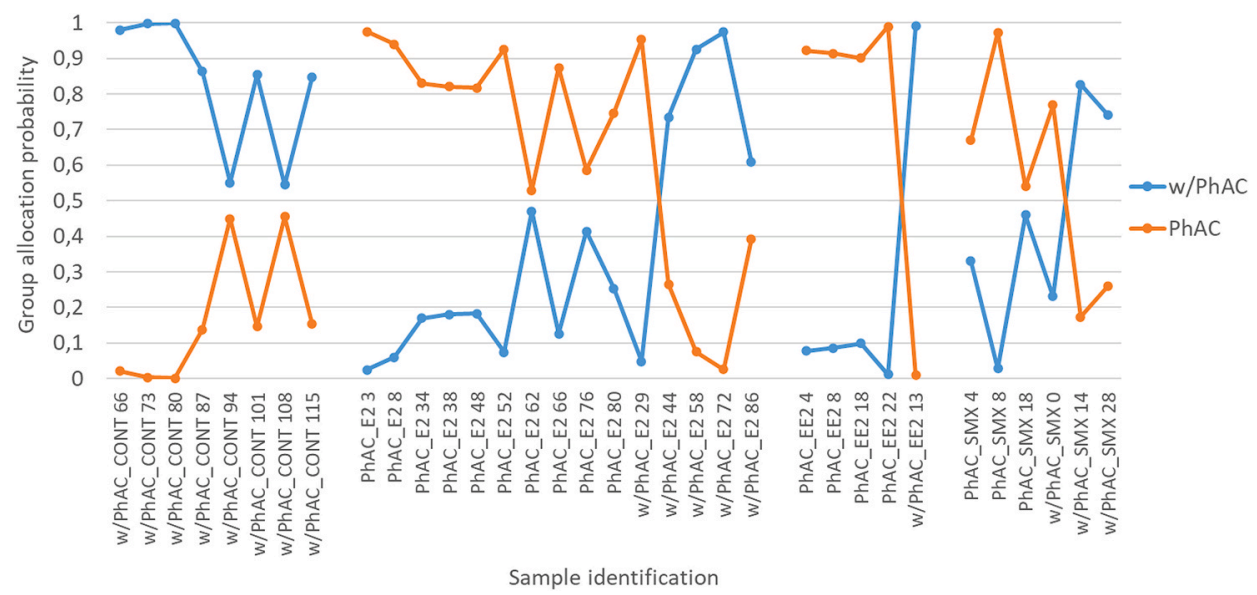

Fig. 9. DA with AGS and QIA data, excluding density, for PhAC addition discrimination. 


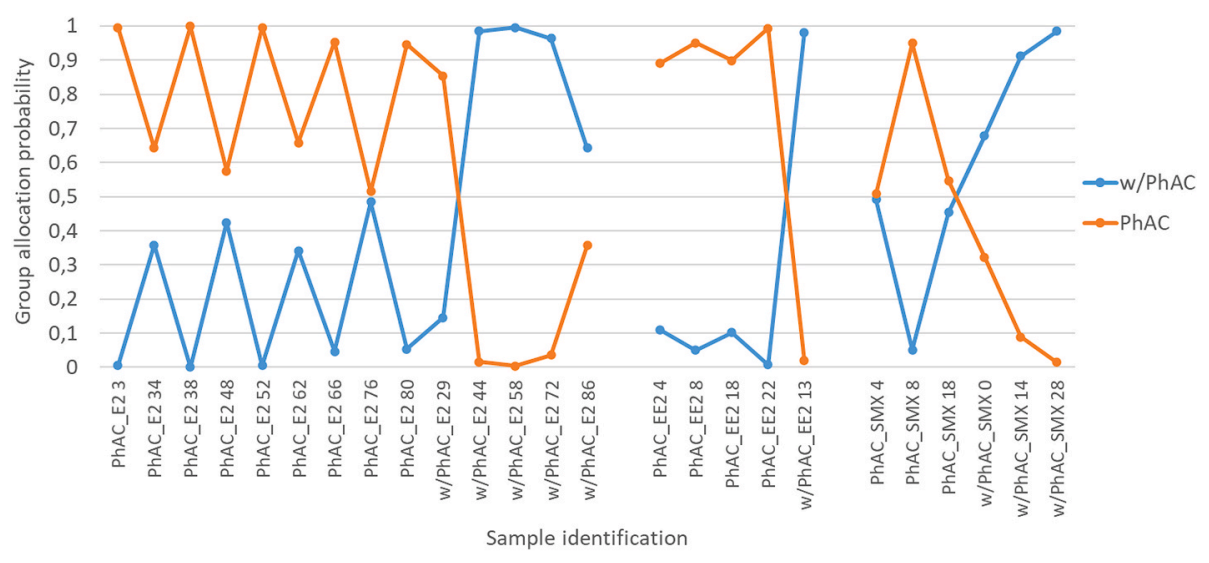

Fig. 10. DA with AGS and QIA data, including density, for PhAC addition discrimination.

granules (G-Nb) contents, large granules fraction (G3-\%V), small flocs fraction (F1-\%A) and the large flocs regularity (F3-Rob). In accordance, an opposite behavior was found between these parameters and the SVI.

On the other hand, the AGS settling properties $\left(\mathrm{SVI}_{5}\right.$ and $\mathrm{SVI}_{30}$ ) were found to correlate positively with the intermediate granules fraction (G2-\%V, opposite to G3-\%V), intermediate flocs size (F2-D and F2-A) and granules regularity (G-Rob, G-Conv, G2-Rob, G2-Conv and G3Conv). In accordance, an opposite behavior was found between these parameters and the granular biomass contents and overall density.

With respect to the floccular biomass contents TSS $_{\text {floc }}$ and VSS floc $_{\text {), }}$ the results showed a close relationship with the overall, small and intermediate flocs contents (F-TA, F-Nb, F1-TA, F1-Nb, F2-TA and F2-Nb) and overall, intermediate and large flocs regularity (F-Conv, F-Rob, F2Conv, F2-Rob and F3-Conv). On the other hand, an opposite behavior was found regarding the flocs apparent density ((VSS/TA) floc), small flocs size (F1-A), intermediate flocs irregularity (F2-Ecc), filamentous bacteria contents (TL, TL/TSS floc and TL/TA floc $_{\text {) }}$ and granular biomass fraction ( $\mathrm{VSS}_{\text {gran }} / \mathrm{VSS}$, opposite to the flocs biomass fraction).

Comparing the obtained results with the former PCA analysis, the establishment of the parameters influencing the overall density, including the small flocs fraction and large flocs irregularity, and the importance of the intermediate flocs size on the AGS settling properties is of notice. Furthermore, it could also be inferred a correlation of the floccular biomass with the flocs contents (projected area and number) and flocs biomass fraction (although indirectly).

\subsection{Discriminant analysis}

Likewise PCA, DA was also performed for the PhAC (E2, EE2, and SMX) dataset, including the control (CONT) experiment when feasible, addressing the SBR-AGS main physical properties and the morphological and structural parameters obtained by QIA. Again, the DA was performed both with and without the biomass density, since no data regarding this parameter could be obtained for the control experiment. The main results of the performed DA, aiming to discriminate the samples with and without PhAC addition (undiscriminating the E2, EE2, SMX, and CONT experiments), are presented in Fig. 9.

The obtained results revealed an overall discrimination of $94.1 \%$ between the operational days with and without PhAC addition, reflecting a $100.0 \%$ accuracy for the samples with $\mathrm{PhAC}$ addition and 92.0\% without. The most important variables were found to be related to the filamentous bacteria presence (TL and TL/TSS), settling ability $\left(\mathrm{SVI}_{5}\right)$, small and intermediate granules fraction (G2-\%V and $\left.\mathrm{G} 1-\% \mathrm{Nb}\right)$ and small flocs contents (F1-Nb). Indeed, significant differences were found for most of these parameters between the two operational periods, particularly for the EE2 and SMX experiments, with the PhAC addition leading to higher SVI and lower intermediate granules fraction and filamentous bacteria contents (data not shown).
In a similar way to the previous DA study, and based on the current dataset, another DA was performed aiming to isolate the samples with and without PhAC addition (undiscriminating the E2, EE2, and SMX experiments), being presented in Fig. 10.

The obtained results showed an overall discrimination of $96.0 \%$ between the operational days with and without PhAC addition, reflecting again a $100.0 \%$ accuracy for the samples with $\mathrm{PhAC}$ addition and $93.8 \%$ without. The most important variables were found to be related to the filamentous bacteria presence (TL), settling properties stability $\left(\mathrm{SVI}_{30} / \mathrm{SVI}_{5}\right)$, large granules regularity (G3-Conv) and small granules contents (G1-Nb). These results can be explained by the lower filamentous bacteria and small granules contents in the PhAC addition experiments (data not shown).

\section{Conclusions}

The AGS, despite the presence of the studied PhAC, presented a predominant granular fraction, consisting mainly of large $(>2.5 \mathrm{~mm})$ granules, a high organic fraction and density, and good settling characteristics. The performed PCA allowed to clearly distinguish, the four operational periods and revealed a positive relationship between the biomass density, sludge settling ability, overall and granular biomass contents, granulation properties, granular biomass fraction and large granules fraction and size. Regarding the floccular biomass, the results showed a close relationship with the flocs contents, size and regularity, and opposing the biomass organic fraction, granular biomass fraction and filamentous bacteria contents. Furthermore, the small flocs fraction and large flocs regularity seem to also play a positive role in the biomass density, contrary to the intermediate (and overall) granules regularity, which seem to have unfavored the sludge settling ability.

The performed DA, allowed for a successful identification (around 95\%) between the operational days with and without PhAC addition. The most important variables were found to be related to the filamentous bacteria contents, sludge settling ability and stability, large granules regularity, granules fraction and small flocs and granules contents.

\section{Declaration of competing interest}

The authors declare that they have no known competing financial interests or personal relationships that could have appeared to influence the work reported in this paper.

\section{Acknowledgments}

The authors thank the Portuguese Foundation for Science and Technology (FCT) under the scope of the strategic funding of UIDB/ 04469/2020 unit and the project AGeNT - PTDC/BTA-BTA/31264/2017 (POCI-01-0145-FEDER-031264). We would also like to thank the 
scientific collaboration under the FCT project UIDB/50016/2020. The authors wish to thank the company Águas do Tejo Atlântico, S.A. for supplying the granules. Cristiano Leal is recipient of a fellowship supported by a doctoral advanced training (call NORTE-69-2015-15) funded by the European Social Fund under the scope of Norte2020 Programa Operacional Regional do Norte. A. Val del Rio is supported by Xunta de Galicia (ED418B 2017/075) and program Iacobus (2018/ 2019). Daniela P. Mesquita and Cristina Quintelas thanks FCT for funding through program DL 57/2016 - Norma transitória. Cristiano Leal also thank to Renê Benevides for all the support during the experimental activities.

\section{Appendix A. Supplementary data}

Supplementary data to this article can be found online at https://doi. org/10.1016/j.jenvman.2021.112474.

\section{Credit author statement}

Cristiano Leal: Data collection, Experiments performing, Writing original draft. Mariana Lopes: Experiments performing. Angeles Val del Río: Experiments performing, Reviewing and editing. Cristina Quintelas: Experiments performing, Reviewing and editing. Paula M.L. Castro: Reviewing and editing. Eugénio C. Ferreira: Reviewing and editing, Funding acquisition. A. Luís Amaral: Conceptualization, Writing reviewing and editing, Supervision. Daniela P. Mesquita: Conceptualization, Writing - reviewing and editing, Supervision.

\section{References}

Amaral, A., 2003. Image Analysis in Biotechnological Processes: Applications to Wastewater Treatment. PhD Thesis, University of Minho.

APHA Standard Methods for the Examination of Water and Wastewater, 23rd Edition, 2017. American Public Health Association, American Water Works Association, Water Environment Federation.

Asensi, E., Zambrano, D., Alemany, E., Aguado, D., 2019. Effect of the addition of precipitated ferric chloride on the morphology and settling characteristics of activated sludge flocs. Separ. Purif. Technol. 227, 115711. https://doi.org/10.1016/ j.seppur.2019.115711.

Balest, L., Lopez, A., Mascolo, G., Di Iaconi, C., 2008. Removal of endocrine disrupter compounds from municipal wastewater using an aerobic granular biomass reactor. Biochem. Eng. J. 41, 288-294. https://doi.org/10.1016/j.bej.2008.05.015.

Beun, J.J., Van Loosdrecht, M.C.M., Heijnen, J.J., 2002. Aerobic granulation in a sequencing batch airlift reactor. Water Res. 36, 702-712. https://doi.org/10.1016/ S0043-1354(01)00250-0.

Caluwé, M., Dobbeleers, T., D'aes, J., Miele, S., Akkermans, V., Daens, D., Geuens, L., Kiekens, F., Blust, R., Dries, J., 2017. Formation of aerobic granular sludge during the treatment of petrochemical wastewater. Bioresour. Technol. 238, 559-567. https://doi.org/10.1016/j.biortech.2017.04.068.

Carrera, P., Mosquera-Corral, A., Méndez, R., Campos, J.L., Val del Rio, A., 2019. Pulsed aeration enhances aerobic granular biomass properties. Biochem. Eng. J. 149, 107244. https://doi.org/10.1016/j.bej.2019.107244.

Combalbert, S., Hernandez-Raquet, G., 2010. Occurrence, fate, and biodegradation of estrogens in sewage and manure. Appl. Microbiol. Biotechnol. 86, 1671-1692. https://doi.org/10.1007/s00253-010-2547-x.

Corsino, S.F., Capodici, M., Torregrossa, M., Viviani, G., 2016. Fate of aerobic granular sludge in the long-term: the role of EPSs on the clogging of granular sludge porosity. J. Environ. Manag. 183 https://doi.org/10.1016/j.jenvman.2016.09.004.

Costa, J.C., Alves, M.M., Ferreira, E.C., 2010. A chemometric tool to monitor high-rate anaerobic granular sludge reactors during load and toxic disturbances. Biochem. Eng. J. 53, 38-43. https://doi.org/10.1016/j.bej.2008.12.006.

Cydzik-Kwiatkowska, A., Wojnowska-Baryła, I., Szatkowski, M., Smoczyński, L., 2013. Biochemical conversions and biomass morphology in a long-term operated SBR with aerobic granular sludge. Desalin. Water Treat. 51, 2261-2268. https://doi.org/ 10.1080/19443994.2012.734695.

De Kreuk, M.K., Heijnen, J.J., Van Loosdrecht, M.C.M., 2005. Simultaneous COD, nitrogen, and phosphate removal by aerobic granular sludge. Biotechnol. Bioeng. 90, 761-769. https://doi.org/10.1002/bit.20470.

Deepnarain, N., Nasr, M., Kumari, S., Stenström, T.A., Reddy, P., Pillay, K., Bux, F., 2019. Decision tree for identification and prediction of filamentous bulking at full-scale activated sludge wastewater treatment plant. Process Saf. Environ. Protect. 126, 25-34. https://doi.org/10.1016/j.psep.2019.02.023.

Ebele, A.J., Abou-Elwafa Abdallah, M., Harrad, S., 2017. Pharmaceuticals and personal care products (PPCPs) in the freshwater aquatic environment. Emerg. Contam. 3, 1-16. https://doi.org/10.1016/j.emcon.2016.12.004.
Farooqi, I.H., Basheer, F., 2017. Treatment of Adsorbable Organic Halide (AOX) from pulp and paper industry wastewater using aerobic granules in pilot scale SBR. J. Water Process Eng. 19, 60-66. https://doi.org/10.1016/j.jwpe.2017.07.005.

Fonseca, A.P., Cardoso, M., Esteves, V., 2013. Determination of estrogens in raw and treated wastewater by high-performance liquid chromatography-ultraviolet detection. J. Environ. Anal. Toxicol. 1-5. https://doi.org/10.4172/21610525.1000203, 04.

Hamza, R.A., Sheng, Z., Iorhemen, O.T., Zaghloul, M.S., Tay, J.H., 2018. Impact of foodto-microorganisms ratio on the stability of aerobic granular sludge treating highstrength organic wastewater. Water Res. 147, 287-298. https://doi.org/10.1016/j. watres.2018.09.061.

Isanta, E., Suárez-Ojeda, M.E., Val del Río, Á., Morales, N., Pérez, J., Carrera, J., 2012. Long term operation of a granular sequencing batch reactor at pilot scale treating a low-strength wastewater. Chem. Eng. J. 198-199, 163-170. https://doi.org/ 10.1016/j.cej.2012.05.066.

Jemaat, Z., Suárez-Ojeda, M.E., Pérez, J., Carrera, J., 2013. Simultaneous nitritation and p-nitrophenol removal using aerobic granular biomass in a continuous airlift reactor. Bioresour. Technol. 150, 307-313. https://doi.org/10.1016/j.biortech.2013.10.005.

Joss, A., Zabczynski, S., Göbel, A., Hoffmann, B., Löffler, D., McArdell, C.S., Ternes, T.A., Thomsen, A., Siegrist, H., 2006. Biological degradation of pharmaceuticals in municipal wastewater treatment: proposing a classification scheme. Water Res. 40, 1686-1696. https://doi.org/10.1016/j.watres.2006.02.014.

Kang, A.J., Brown, A.K., Wong, C.S., Yuan, Q., 2018. Removal of antibiotic sulfamethoxazole by anoxic/anaerobic/oxic granular and suspended activated sludge processes. Bioresour. Technol. 251, 151-157. https://doi.org/10.1016/j. biortech.2017.12.021.

Kent, J., Tay, J.H., 2019. Treatment of $17 \alpha$-ethinylestradiol, 4-nonylphenol, and carbamazepine in wastewater using an aerobic granular sludge sequencing batch reactor. Sci. Total Environ. 652, 1270-1278. https://doi.org/10.1016/j. scitotenv.2018.10.301.

Kim, Y.J., Choi, S.J., Bae, H., Kim, C.W., 2011. Sludge settleability detection using automated SV30 measurement and its application to a field WWTP. Water Sci. Technol. 64, 1743-1749. https://doi.org/10.2166/wst.2011.078.

Lang, L., Wan, J., Zhang, J., Wang, J., Wang, Y., 2015. Interaction between phosphorus removal and hybrid granular sludge formation under low hydraulic selection pressure at alternating anaerobic/aerobic conditions. Environ. Technol. 36, 2746-2754. https://doi.org/10.1080/09593330.2015.1045943.

Leal, C., Amaral, A.L., Costa, M. de L., 2016. Microbial-based evaluation of foaming events in full-scale wastewater treatment plants by microscopy survey and quantitative image analysis. Environ. Sci. Pollut. Res. 23, 15638-15650. https://doi. org/10.1007/s11356-016-6750-x.

Leal, C., Val del Río, A., Mesquita, D.P., Amaral, A.L., Castro, P.M.L., Ferreira, E.C., 2020a. Sludge volume index and suspended solids estimation of mature aerobic granular sludge by quantitative image analysis and chemometric tools. Separ. Purif. Technol. 234, 116049. https://doi.org/10.1016/j.seppur.2019.116049.

Leal, C.S., Mesquita, D.P., Amaral, A.L., Amaral, A.M., Ferreira, E.C., 2020 b. Environmental impact and biological removal processes of pharmaceutically active compounds: the particular case of sulfonamides, anticonvulsants and steroid estrogens. Crit. Rev. Environ. Sci. Technol. 50, 698-742. https://doi.org/10.1080/ 10643389.2019.1642831.

Liu, L., You, Q., Fan, H., Huang, X., Wei, L., Liu, C., 2019. Behavior of antibiotics and antibiotic resistance genes in aerobic granular reactors: interrelation with biomass concentration. Int. Biodeterior. Biodegrad. 139, 18-23. https://doi.org/10.1016/j ibiod.2019.02.004.

Liu, Y.Q., Tay, J.H., Moy, B.Y.P., 2006. Characteristics of aerobic granular sludge in a sequencing batch reactor with variable aeration. Appl. Microbiol. Biotechnol. 71, 761-766. https://doi.org/10.1007/s00253-005-0209-1.

Long, B., Xuan, X., Yang, C., Zhang, L., Cheng, Y., Wang, J., 2019. Stability of aerobic granular sludge in a pilot scale sequencing batch reactor enhanced by granular particle size control. Chemosphere 225, 460-469. https://doi.org/10.1016/j. chemosphere.2019.03.048.

Mendes Barros, A.R., Argenta, T.S., de Amorim de Carvalho, C., da Silva Oliveira, F., Milen Firmino, P.I., Bezerra dos Santos, A., 2021. Effects of the antibiotics trimethoprim (TMP) and sulfamethoxazole (SMX) on granulation, microbiology, and performance of aerobic granular sludge systems. Chemosphere 262. https://doi.org/ 10.1016/j.chemosphere.2020.127840.

Mesquita, D.P., Amaral, A.L., Ferreira, E.C., 2016. Estimation of effluent quality parameters from an activated sludge system using quantitative image analysis. Chem. Eng. J. 285, 349-357. https://doi.org/10.1016/j.cej.2015.09.110.

Mesquita, D.P., Amaral, A.L., Ferreira, E.C., 2011a. Identifying different types of bulking in an activated sludge system through quantitative image analysis. Chemosphere 85, 643-652. https://doi.org/10.1016/j.chemosphere.2011.07.012.

Mesquita, D.P., Amaral, A.L., Ferreira, E.C., 2011b. Characterization of activated sludge abnormalities by image analysis and chemometric techniques. Anal. Chim. Acta 705, 235-242. https://doi.org/10.1016/j.aca.2011.05.050.

Mesquita, D.P., Dias, O., Amaral, A.L., Ferreira, E.C., 2008. Relationship Between Sludge Volume Index and Biomass Structure Within Activated Sludge Systems Atas do XVII COBEQ - Congresso Brasileiro de Engenharia Quimica. (Recife) CD-ROM, p. 7.

Mills, M.R., Arias-Salazar, K., Baynes, A., Shen, L.Q., Churchley, J., Beresford, N., Gayathri, C., Gil, R.R., Kanda, R., Jobling, S., Collins, T.J., 2015. Removal of ecotoxicity of $17 \alpha$-ethinylestradiol using TAML/peroxide water treatment. Sci. Rep. 5, 1-10. https://doi.org/10.1038/srep10511.

Nieto, A., Borrull, F., Marcé, R.M., Pocurull, E., 2007. Selective extraction of sulfonamides, macrolides and other pharmaceuticals from sewage sludge by pressurized liquid extraction. J. Chromatogr. A 1174, 125-131. https://doi.org/ 10.1016/j.chroma.2007.09.068. 
Paulo, A.M.S., Amorim, C.L., Costa, J., Mesquita, D.P., Ferreira, E.C., Castro, P.M.L., 2021. Long-term stability of a non-adapted aerobic granular sludge process treating fish canning wastewater associated to EPS producers in the core microbiome. Sci. Total Environ. 756, 144007. https://doi.org/10.1016/j.scitotenv.2020.144007.

Quintelas, C., Mesquita, D.P., Ferreira, E.C., Amaral, A.L., 2019. Quantification of pharmaceutical compounds in wastewater samples by near infrared spectroscopy (NIR). Talanta 194, 507-513. https://doi.org/10.1016/j.talanta.2018.10.076.

Rusanowska, P., Cydzik-Kwiatkowska, A., Świątczak, P., Wojnowska-Baryła, I., 2019. Changes in extracellular polymeric substances (EPS) content and composition in aerobic granule size-fractions during reactor cycles at different organic loads. Bioresour. Technol. 272, 188-193. https://doi.org/10.1016/j.biortech.2018.10.022.

Sanderson, H., Brain, R.A., Johnson, D.J., Wilson, C.J., Solomon, K.R., 2004. Toxicity classification and evaluation of four pharmaceuticals classes: antibiotics, antineoplastics, cardiovascular, and sex hormones. Toxicology 203, 27-40. https:// doi.org/10.1016/j.tox.2004.05.015.

Ting, Y.F., Praveena, S.M., 2017. Sources, mechanisms, and fate of steroid estrogens in wastewater treatment plants: a mini review. Environ. Monit. Assess. 189, 178. https://doi.org/10.1007/s10661-017-5890-x.

Verawaty, M., Tait, S., Pijuan, M., Yuan, Z., Bond, P.L., 2013. Breakage and growth towards a stable aerobic granule size during the treatment of wastewater. Water Res. 47, 5338-5349. https://doi.org/10.1016/j.watres.2013.06.012.
Vergili, I.G., Sezin, 2017. Removal of organic matter and etodolac from pharmaceutical industry wastewater by PAC adsorption. Water Environ. Res. 89, 641-651. https:// doi.org/10.2175/106143017X14902968254520.

Wei, D., Zhang, K., Wang, S., Sun, B., Wu, N., Xu, W., Du, B., Wei, Q., 2017. Characterization of dissolved organic matter released from activated sludge and aerobic granular sludge biosorption processes for heavy metal treatment via a fluorescence approach. Int. Biodeterior. Biodegrad. 124, 326-333. https://doi.org/ 10.1016/j.ibiod.2017.03.018.

Weltje, L., Sumpter, J.P., 2017. What makes a concentration environmentally relevant? Critique and a proposal. Environ. Sci. Technol. 51, 11520-11521. https://doi.org/ 10.1021/acs.est.7b04673.

Xiong, W., Wang, L., Zhou, N., Fan, A., Wang, S., Su, H., 2020. High-strength anaerobic digestion wastewater treatment by aerobic granular sludge in a step-by-step strategy. J. Environ. Manag. 262, 110245. https://doi.org/10.1016/j.jenvman.2020.110245.

Xue, W., Hao, T., Mackey, H.R., Li, X., Chan, R.C., Chen, G., 2017. The role of sulfate in aerobic granular sludge process for emerging sulfate-laden wastewater treatment. Water Res. 124, 513-520. https://doi.org/10.1016/j.watres.2017.08.009.

Yuan, S., Gao, M., Zhu, F., Afzal, M.Z., Wang, Y.K., Xu, H., Wang, M., Wang, S.G., Wang, X.H., 2017. Disintegration of aerobic granules during prolonged operation. Environ. Sci. Water Res. Technol. 3, 757-766. https://doi.org/10.1039/ c7ew00072c. 